\title{
Optical and electric manifestations of incommensurate phase in $\mathrm{NH}_{4} \mathrm{HSeO}_{4}$ crystals
}

\author{
B.V.Andriyevsky ${ }^{1}$, Z.Czapla ${ }^{2}$, S.Dacko ${ }^{2}$, \\ O.Ya.Myshchyshyn 1 \\ 1 The Ivan Franko National University of Lviv, \\ 8 Kyryla and Mefodiya Str., 79005 Lviv, Ukraine \\ 2 Institute of Experimental Physics, Wroclaw University, \\ 9 M.Borna Sq., Wroclaw, Poland
}

Received September 9, 1998, in final form September 15, 1999

\begin{abstract}
Temperature dependences of the optical path difference by the variable part of refractive index $D=(n-1) l$ and the components $\varepsilon^{\prime}$ and $\varepsilon^{\prime \prime}$ of complex dielectric permittivity for $\mathrm{NH}_{4} \mathrm{HSeO}_{4}$ single crystal are studied in the temperature range of $220-300 \mathrm{~K}$. Anomalous behaviour of these dependences in the range of incommensurate phase 250-262 K was observed. Analysis of the results of dielectric investigation predicts a considerable decrease of the coefficient of elastic stiffness $C$ in the narrow temperature range of 256-260 K at the transition from the paraelectric to incommensurate phase.
\end{abstract}

Key words: ferroelectrics, incommensurate phase, optical properties, dielectric properties

PACS: 77.80.Bh, 77.84.Fa, 78.20.Ci

\section{Introduction}

The ammonium biselenate single crystal, $\mathrm{NH}_{4} \mathrm{HSeO}_{4}$ (AHSe), is characterized by several phase transitions (PT). Below the melting temperature $T_{m}=427 \mathrm{~K}$, the crystal possesses a superionic conductive phase $I$. Paraelectric (PE) monoclinic phase $I I$ is characterized by spatial symmetry $C_{2}^{3}$ and by piroelectric polarization along the $b$-axis [1]. The lower limit of this phase is ascribed by many investigators to the temperature $T_{23}=T_{i}=262 \mathrm{~K}[1-6]$. The phase $I I I$ is an incommensurate (IC) one [7] and is limited by the temperature $T_{34}=T_{c}=250 \mathrm{~K}$ from the lower side. The AHSe crystal exhibits the ordered ferroelectric-ferroelastic phase $I V$ in the temperature range between 100 and $250 \mathrm{~K}$. The phase $V$ below $T_{45}=100 \mathrm{~K}$ is nonferroelectric [1]. The PTs at 100, 250, and $406 \mathrm{~K}$ in AHSe are regarded as 
being of a discontinuous type (first order). It was established that the changes of physical parameters at the $I V \leftrightarrow V$ phase transition exceed those occurring at the $I I I \leftrightarrow I V$ and $I I \leftrightarrow I I I$ phase transitions [1].

The crystal under study is characterized by a weak ferroelectric (FE) PT $\left(\Delta P_{s} \leqslant\right.$ $\left.0.5 \cdot 10^{-2} \mathrm{C} / \mathrm{m}^{2}\right)$ at $250 \mathrm{~K}[1,2]$. Therefore, this PT manifests itself in comparatively small anomalies in the temperature dependences of different physical parameters, that complicates the experimental studies of the PT. For the wavelength $\lambda=632.8 \mathrm{~nm}$ of a He-Ne laser, the refractive indices of AHSe are as follows: $n_{a}=1.5452, n_{b}=1.5891$, $n_{c}=1.53145$. Hence, the crystal is characterized by relatively high birefringence $\Delta n \approx 0.06$ [8]. The experimental results on the temperature dependences of optical birefringence of AHSe $[9,10]$ are rather ambiguous. The temperature dependences of dielectric permittivity $\varepsilon^{\prime}(T)$ of AHSe were studied earlier [1-5]. One maximum of this dependence has been found at $250 \mathrm{~K}$, which was explained by the transition from the IC to the ferroelectric phase. But no peculiarities of this dependence have been found in the range of IC phase 250-262 K. (Characteristic anomalies of the temperature dependence of physical parameters in the IC phase have been found in $\alpha$ - $\mathrm{ZnP}_{2}$ crystals [13], for example).

The main purpose of this work was to perform precise measurements of the temperature dependences of optical path differences and dielectric permittivity of AHSe crystal in the range of IC phase.

\section{Experimental}

The temperature measurements of optical path difference (OPD), $D=(n-1) l$, by a variable part of refractive index (VPRI), $(n-1)=\eta$, were performed using the laser interferometer of the Jamen type [11]. Measurements of the temperature dependence of light intensity were carried out in the scanning mode in the heating regime. The error of determining the $\mathrm{OPD}$ was $\delta D / D \sim 10^{-5}$ in our case of the sample thickness $l=5 \mathrm{~mm}$ and refractive index $n \approx 1.5$.

A $b$-cut sample was prepared for the dielectric measurements. Gold electrodes were evaporated on the $b$-faces. The sample was placed in vacuum $\left(p=5 \cdot 10^{-3} \mathrm{~Pa}\right)$ on the copper plate cooling by nitrogen gas, and it was mechanically free. The temperature in the chamber was controlled with an accuracy not worse than $5 \cdot 10^{-3} \mathrm{~K}$. The precision LCR-meter HP 4284A was used for the dielectric measurements. The below discussed results were obtained at a frequency of $1 \mathrm{MHz}$, a measuring field of $3 \mathrm{~V} / \mathrm{cm}$, and a cooling rate of $0.17 \mathrm{~K} / \mathrm{min}$.

\section{Results and discussion}

The measurements of the temperature dependences of the relative change of OPD $\mathrm{d} D / D$ did not reveal clearly noticeable anomalies in the regions of the known $P T s$ at $T_{c}=250 \mathrm{~K}$ and $T_{i}=262 \mathrm{~K}$. Performing additional measurements of the linear thermal expansion of the same samples of AHSe, we have not observed such characteristic anomalies as well. The previous studies of linear thermal expansion of AHSe 
[12] show that one cannot easily notice these anomalies in the typical temperature dependence of OPD. To reveal the characteristic features on the temperature dependences of the relative change of OPD $\mathrm{d} D / D$ of AHSe connected with PTs, we have used the temperature dependences of derivative $\mathrm{d} / \mathrm{d} T(\mathrm{~d} D / D)$. It is seen from figure 1, that a significant minimum is formed by the two parts of the temperature dependences of $\mathrm{d} / \mathrm{d} T(\mathrm{~d} D / D)$ of different character, below and above the $P T$ point $T_{i}=262 \mathrm{~K}$. A small maximum of absolute magnitude of the temperature derivative of OPD is observed near the temperature of $T_{c}=250 \mathrm{~K}$ on different curves. The temperature derivative $\mathrm{d} / \mathrm{d} T(\mathrm{~d} D / D)$ of AHSe in the IC phase is substantially different from those observed in the PE and FE phases (figure 1). Thus, the behaviour of the temperature dependence of the relative change of OPD $\mathrm{d} D / D$ in the IC phase of AHSe crystals can be treated as the anomalous one, when compared with those for the PE and FE phases.

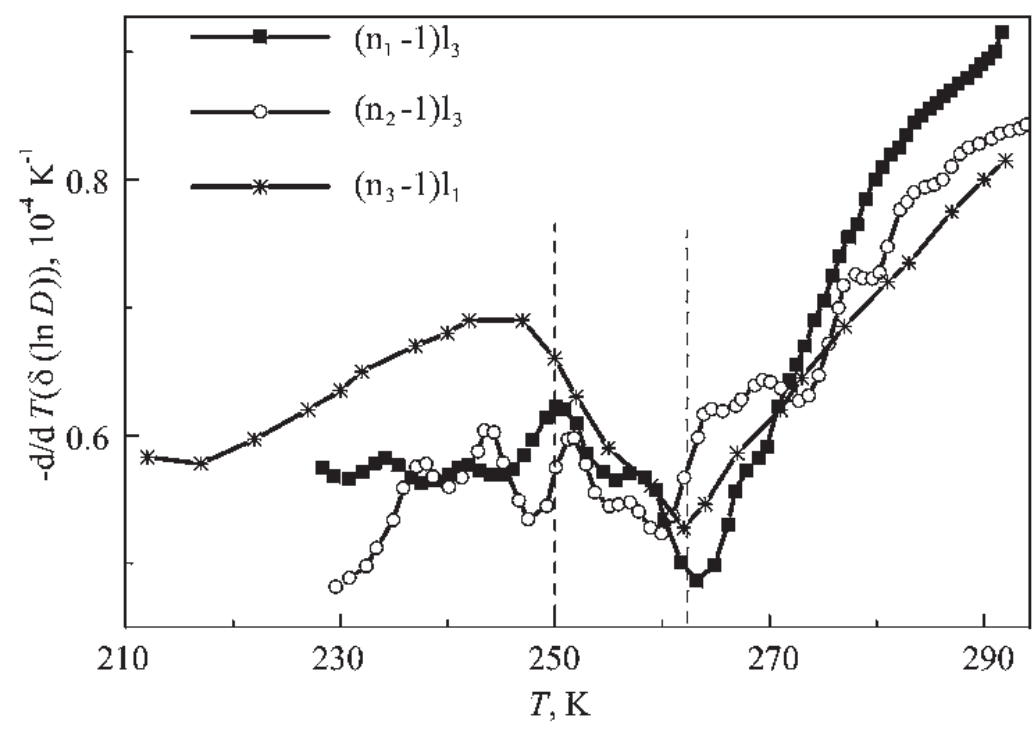

Figure 1. Temperature dependences of the derivatives of the relative change of optical path difference related to the variable part of refractive index $\mathrm{d} / \mathrm{d} T\left(\delta\left(\ln D_{13}\right)\right), \mathrm{d} / \mathrm{d} T\left(\delta\left(\ln D_{23}\right)\right)$ and $\mathrm{d} / \mathrm{d} T\left(\delta\left(\ln D_{31}\right)\right)$ for AHSe crystal

Since the PT at $T_{i}=262 \mathrm{~K}$ is of second order, a characteristic break of temperature dependence of the relative $\mathrm{OPD} \mathrm{d} D / D$ and the jump of temperature dependence of its derivative $\mathrm{d} / \mathrm{d} T(\mathrm{~d} D / D)$ should be seen. However, our results have not shown any notable anomalies of such types for these parameters. We suppose that the expected characteristic temperature anomalies of OPD studied for the first- and second-order PTs at 250 and $262 \mathrm{~K}$ in AHSe are so small, that they can be camouflaged by the thermal fluctuation effects.

Dielectric measurements along the ferroelectric $b$-axes of AHSe at the frequency of $1 \mathrm{MHz}$, exceeding the resonance frequency by one order of magnitude, showed the convergent sequence of the maxima for both components of the dielectric permittivity $\varepsilon^{\prime}$ and $\varepsilon^{\prime \prime}$ in the range of IC phase at different rates of heating and cooling run (figure 2). 


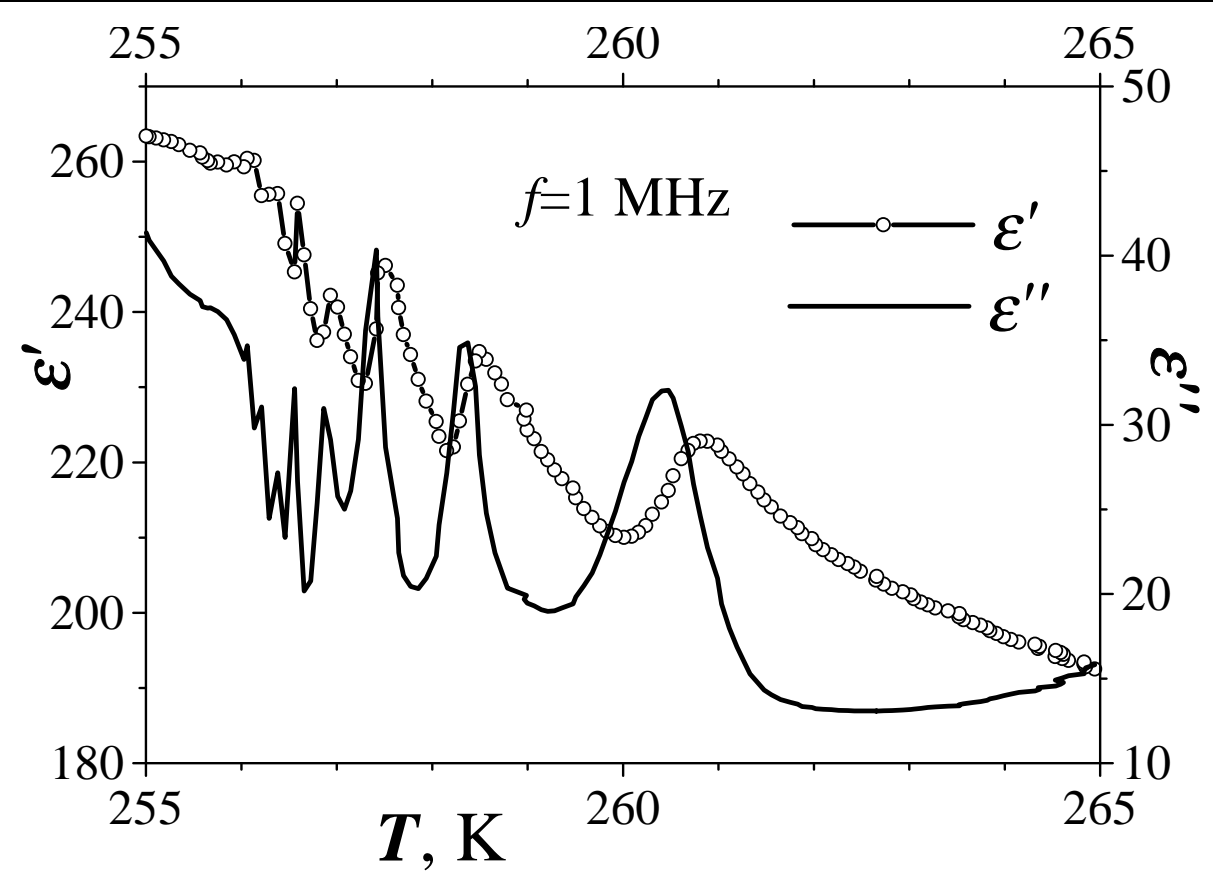

Figure 2. Temperature dependences of the real $\varepsilon^{\prime}$ and imaginary parts $\varepsilon^{\prime \prime}$ of dielectric permittivity of AHSe crystal for the frequency of $1 \mathrm{MHz}$ at cooling run of $0.17 \mathrm{~K} / \mathrm{min}$

The presence of temperature dependence of the wave vector $q$ is well known in the range of IC phase of crystals. In some cases different temperature subranges in the IC phase with different $q$ arise, forming the so-called devil staircase (see, for example, [13]). Taking this into account, we could attribute the observed temperature sequence of the dielectric permittivity in the IC phase of AHSe to the boundaries between the commensurate phases with different characteristic wave vectors. Indeed, this sequence looks like the known devil staircase. But a detailed analysis shows that the positions of these extrema are different for different frequencies of the measured electrical field. This testifies to the resonance character of the periodic structure observed, which can be classified as manifestation of overtones due to the great temperature change of the coefficient of elastic stiffness $C$ of the crystal in the IC phase. Really, one can take into account the known relation between resonance frequencies of the sample $f_{R}^{(n)}$, its characteristic dimension $l$, density $\rho$ and coefficient of elastic stiffness $C$ of the material,

$$
f_{R}^{(n)}=\frac{n}{2 l} \sqrt{ } \frac{C}{\rho}
$$

where $n=1,2,3 \ldots$. Neglecting the temperature dependences of the length $l$ and the density $\rho$, one can obtain the condition for observing the sequence of vibration resonances (overtones) with different numbers of $n$ value at one frequency ( $f=1 \mathrm{MHz}$ $\left.=f_{R}^{(n)}\right)$ : 


$$
C(T)=\frac{4 l^{2} \rho f_{R}^{(n) 2}}{n^{2}}
$$

Substituting the known values $l, \rho$ and $f_{R}^{(n)}=1 \mathrm{MHz}$ into the formula (2), one can obtain the relation between the values $C$ and $n$. The analysis of the $\varepsilon^{\prime}(f)$ and $\varepsilon^{\prime \prime}(f)$ frequency dependences testifies to the fact that the main resonance frequency $(n=1)$ of the sample studied is equal to $f_{R} \approx 250 \mathrm{kHz}$ at the temperature $T \approx 261.5 \mathrm{~K}$. Therefore, the maximum of $\varepsilon^{\prime \prime}(T)$ dependence at the temperature $T \approx 261.5 \mathrm{~K}$ for the frequency $1 \mathrm{MHz}$ in figure 2 corresponds to the forth overtone, $n=4$. In such a case the numbers of the other maxima on this dependence are determined uniquely, which permits to calculate the dependence $C(n)$, using the formulae (2), and to obtain a corresponding dependence of $C(T)$. The result of such calculations is presented in figure 3 .

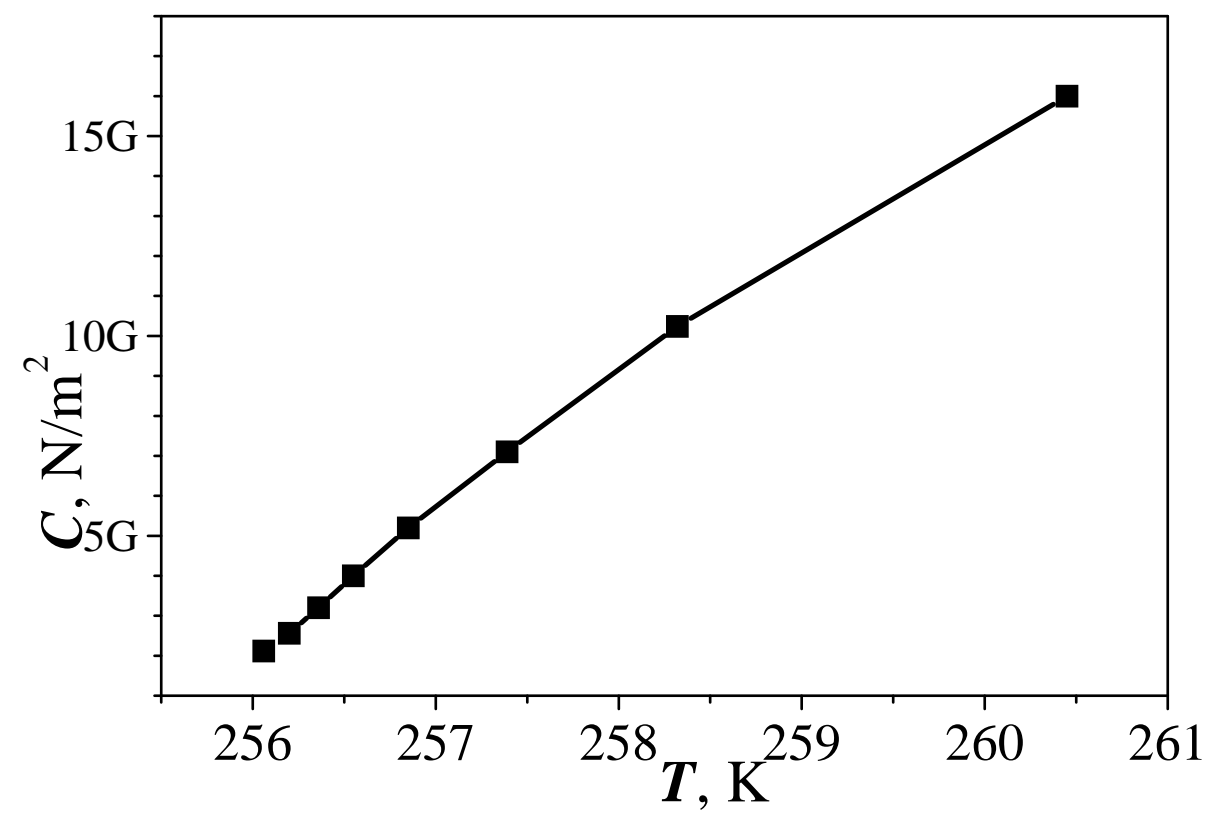

Figure 3. Temperature dependence of the elastic stiffness $C$ of AHSe crystal in the IC phase defined from dielectric measurements. (The label $\mathrm{G}$ of the $y$-axis denotes prefix "giga")

Thus, the presence of several extrema of the $\varepsilon^{\prime}(T)$ and $\varepsilon^{\prime \prime}(T)$ dependences in the narrow temperature range for one value of frequency $1 \mathrm{MHz}$ is explained by a considerable temperature dependence of the coefficient of elastic stiffness $C(T)$ for AHSe crystal.

\section{Conclusion}

1. Temperature dependence of the derivative of optical path difference by the variable part of refractive index $\mathrm{d} / \mathrm{d} T[(n-1) l]$ of AHSe crystals is characterized by a significant extremum at the transition from PE to IC phase at $T_{i}=262 \mathrm{~K}$. 
An anomalous temperature behaviour of this parameter in IC phase when compared with a rather different behaviour in PE and FE phases can be also pointed out. Temperature changes of the optical parameters at the IC-FE phase transition $\left(T_{c}=250 \mathrm{~K}\right)$ of AHSe are substantially smaller than those at the PE-IC phase transition $\left(T_{i}=262 \mathrm{~K}\right)$.

2. The analysis of the results of dielectric investigation of AHSe crystals predicts a considerable decrease of the coefficient of elastic stiffness $C$ in a narrow temperature range $256-260 \mathrm{~K}$ of IC phase.

\section{References}

1. Czapla Z., Pykacz H., Sobczyk L. Ferroelectricity and isotopic effect in $\mathrm{NH}_{4} \mathrm{HSeO}_{4}$. // Ferroelectrics, 1987, vol. 76, p. 291-301.

2. Czapla Z., Lis T., Sobczyk L. Ferroelectric properties of $\mathrm{NH}_{4} \mathrm{HSeO}_{4}$ crystals. // Phys. Stat. Sol. (a), 1979, vol. 51, No. 2, p. 609-612.

3. Pykacz H., Mroz J., Czapla Z. On the existence of the incommensurate phase in $\mathrm{NH}_{4} \mathrm{HSeO}_{4}$ crystals. // Acta Phys. Polon., 1986, vol. A70, No. 5, p. 553-557.

4. Pykacz H. Dielectric hysteresis in the incommensurate phase of $\mathrm{NH}_{4} \mathrm{HSeO}_{4}$ under electric field. // Solid State Commun., 1988, vol. 66, No. 5, p. 567-570.

5. Majszczyk J., Raczka J., Czapla Z. A new phase transition in $\mathrm{NH}_{4} \mathrm{HSeO}_{4}$ crystals. // Phys. Stat. Sol. (a), 1981, vol. 67, No. 2, p. K123-K125.

6. Kityk A.V., Vlokh O.G., Zadorozhna A.V., Czapla Z. On the pressure-temperature phase diagram of $\mathrm{NH}_{4} \mathrm{HSeO}_{4}$ crystal: acoustic treatment. // Ferroelectrics Letters, 1994, vol. 17, p. 1-4.

7. Aleksandrova I.P., Moskvich Yu.A., Rosanov O.V., Sukhovsky Yu.A. Dislocations and time dependent dynamic of the incommensurate phase of $\mathrm{NH}_{4} \mathrm{HSeO}_{4}$. // Ferroelectrics: Lett. Sec., 1984, vol. 1, No. 5-6, p. 131-134.

8. Andriyevsky B., Czapla Z., Myshchyshyn O. Optical properties and phase transitions in $\mathrm{NH}_{4} \mathrm{HSeO}_{4}$ crystals. // Phys. Stat. Sol. (a), 1998, vol. 165, No. 2, p. 495-502.

9. Martynov V.G., Anistratov A.T. Optical and electrooptical properties of $\mathrm{NH}_{4} \mathrm{HSeO}_{4}$ in the vicinity of ferroelectric phase transition. // Solid State Physics, 1982, vol. 24, No. 7, p. 2013-2015 (in Russian).

10. Kroupa J., Fousek J., Czapla Z. Proof of the existence of the Lifshitz point in $\mathrm{NH}_{4} \mathrm{HSeO}_{4}$. // Ferroelectrics, 1988, vol. 79, p. 291-294.

11. Andriyevsky B.V., Romanyuk M.O. Temperature changes determination of refractive index and thickness of material in one optical-interference experiment. // Proceedings of SPIE, 1995, vol. 2648, p. 251-256.

12. Dziedzic J., Poprawski R. Dilatometric studies of phase transitions in $\mathrm{NH}_{4} \mathrm{HSeO}_{4}$ crystals. // Ferroelectrics, 1988, vol. 77, p. 1-6.

13. Sheleg A.U., Zaretskii V.V. $X$-ray study of the commensurate-incommensurate phase transitions in $\alpha-\mathrm{ZnP}_{2} / /$ Phys. Stat. Sol. (a), 1984, vol. 86, No. 2, p. 517-523. 


\title{
Оптичні та діелектричні прояви несумірної фази в кристалах $\mathrm{NH}_{4} \mathrm{HSeO}_{4}$
}

\author{
Б.В.Андрієвський ${ }^{1}$, З.Чапля ${ }^{2}$, С.Дацко ${ }^{2}$, \\ О.Я.Мищишин ${ }^{1}$ \\ 1 Львівський національний університет ім. І.Франка, \\ 79005 Львів, вул. Кирила і Мефодія, 8 \\ 2 Інститут експериментальної фізики Вроцлавського університету, \\ Польща, Вроцлав, пл. М.Борна, 9
}

Отримано 9 вересня 1998 р., в остаточному вигляді 15 вересня $1999 \mathrm{p}$.

Досліджено температурні залежності різниці оптичних шляхів за змінною частиною показника заломлення $D=(n-1) l$ та компонент $\varepsilon^{\prime}$ i $\varepsilon^{\prime \prime}$ комплексної діелектричної проникливості для монокристала $\mathrm{NH}_{4} \mathrm{HSeO}_{4}$ в області температур 220-300 K. Виявлено аномальну поведінку цих залежностей в області несумірної фази 250-262 К. Аналіз результатів діелектричних досліджень свідчить про значне зменшення коефіцієнта пружної жорсткості $C$ у вузькій температурній області 256-260 К при переході з параелектричної у несумірну фазу.

Ключові слова: сегнетоелектрики, несумірна фаза, оптичні властивості, діелектричні властивості

PACS: $77.80 \mathrm{Bh}, 77.84 \mathrm{Fa}, 78.20 \mathrm{Ci}$ 
